\title{
Selenium Supplementation in Obese Patients with Subclinical Hypothyroidism and Type 2 Diabetes
}

\author{
Guarino $\mathrm{G}^{1}$, Ragozzino $\mathrm{G}^{1}$, Della Corte $\mathrm{T}^{1}$, Fontana $\mathrm{S}^{1}$, Strollo $\mathrm{F}^{2}$, Cecaro $\mathrm{M}^{3}$, and Gentile $\mathrm{S}^{* 1}$ \\ ${ }^{1}$ Department of Experimental and Clinical Medicine, University of Campania "Luigi Vanvitelli", Naples, Italy \\ ${ }^{2}$ Department of Pharmacology and Biomolecular Sciences, University of Milan, Italy \\ ${ }^{3}$ Register of Biologist, Salerno, Italy
}

*Corresponding author: Gentile S (2018) Department of Experimental and Clinical Medicine, University of Campania “Luigi Vanvitelli", Naples, Italy, E-mail: s.gentile1949@gmail.com

Citation: Guarino G, Ragozzino G, Della Corte T, Fontana S, Strollo F, et al. (2018) Selenium Supplementation in Obese Patients with Subclinical Hypothyroidism and Type 2 Diabetes. J Nutri Health Sci 5(2): 202. doi: 10.15744/2393-9060.5.202

Received Date: March 23, 2018 Accepted Date: April 03, 2018 Published Date: April 12, 2018

\begin{abstract}
Selenium (Se) is a trace element present in many foods. Selenium-protein co-factor plays a critical anti-oxidant and anti-inflammatory role in thyroid function, but quite recently its ability to prevent adipocyte hypertrophy and adipogenesis has also been evaluated. The aim of our study was to assess whether thyroid function, as well as, body mass index (BMI) and body composition might improve in Setreated obese patients as compared to those getting placebo (P). 50 obese patients $\left(\mathrm{BMI} \geq 30 \mathrm{~kg} / \mathrm{m}_{1}^{2}\right)$ with non-autoimmune subclinical hypothyroidism participated in the study. They were randomized to either Se (Se Group, SG, L-seleno-methionine $83 \mathrm{mcg} / \mathrm{day}$ ) or P (P Group, PG) and underwent a low-calorie diet. BMI, homeostatic model assessment-based insulin resistance (HOMA-IR), TSH, FT4, as well as, Vi-SCAN bioimpedance assessed waist circumference (WC) and \% visceral fat (\%VF) were evaluated both at baseline and 6 plus 12 months after treatment start. The SG showed a significant decrease in TSH at 6 and 12 months as compared to the PG, might be through the well-known selenium ability to modulate thyroid hormone synthesis. The SG also displayed a significant decrease in BMI, WC and \%VF in support to our original hypothesis of a strong association of visceral obesity with low Se intake rates.
\end{abstract}

Keywords: Type 2 Diabetes; Subclinical Hypothyroidism; Selenium Supplementation; Obese Patients

\section{Introduction}

Morbid obesity is associated with multiple co-morbidities, such as type 2 diabetes mellitus (T2DM), hypertension (HT), dyslipidemia (DL), and obstructive sleep apnea syndrome [1]. It is not commonly appreciated that morbid obesity is also associated with an increased prevalence of subclinical hypothyroidism ( $\mathrm{SH}$ ). The underlying pathophysiology of obesity related SH is not completely understood. High leptin levels and insulin-resistance appear to play a role, possibly by inducing a reset of the central thyrostat [2]. In the general population $\mathrm{SH}$ is diagnosed 3-4 times more frequently in women than in men and its prevalence varies from 4 to $9 \%$, and it $[3,4]$. SH is associated with an increased risk of death from all causes as well as from cardiovascular diseases (CVD) [3]. The prevalence of hypothyroidism appears to be higher in morbidly obese than in not obese patients [3]. SH-related hypercholesterolemia (HC), impaired left ventricular diastolic function, endothelial dysfunction and increased C-reactive protein levels have been proposed as etiologic factors [5]. Consideration of thyroid hormone treatment for SH in the general population is gaining in strength [3] and in obese patients with additional risks of CVD the indication for SH treatment may even be stronger.

The relationship between weight loss and serum TSH levels is well documented. In SH patients bariatric surgery dependent percent excess weight loss (\%EWL) - defined as weight loss divided by excess weight as referred to $25 \mathrm{~kg} / \mathrm{m}^{2} \mathrm{BMI}-\mathrm{was}$ associated to decreased serum TSH levels from $5.82 \pm 2.05 \mathrm{mU} / \mathrm{L}$ preoperatively to $2.78 \pm 1.31 \mathrm{mU} / \mathrm{L}$ at 12 months $(\mathrm{P}<0.001)$. A subset of morbidly obese patients may thus display transient hypothyroidism vanishing after major weight loss. Moreover a weak positive correlation is found between BMI and TSH, suggesting that the prevalence of SH is BMI dependent [6].

The exact mechanism leading to elevated TSH levels in obesity is not known. TSH secretion is also affected by other endocrine factors including leptin, dopamine and serotonin [7]. Most evidences suggest that leptin plays a major role: it has been reported to enhance TSH production and its levels not only increase in morbid obesity but also positively correlate with mean 24-hour TSH levels [8]. In contrast, dopamine and serotonin exert suppressive effects on TSH secretion and brain reduced dopaminergic and serotoninergic tone has been suggested as a further TSH increasing factor in obesity [7,8]. However, the high prevalence of elevated TSH levels in obesity might also be due to SH as a result of an increased prevalence of Hashimoto disease. This hypothesis was tested by Rotondi et al. who measured circulating antibodies against thyroglobulin (anti-Tg) and thyro-peroxidase (anti- 
TPO) in a group of 350 obese patients with a mean BMI of $48.8 \pm 6.7 \mathrm{~kg} / \mathrm{m}^{2}$ [9]. In fact they found their prevalence (11\%) was similar to that found in the general population and, in case of associated SH, was even $50 \%$ lower in obese than in normal weight patients. Both findings indicate that morbid obesity is not associated with increased thyroid autoimmunity.

On the other hand, T4 and T3 thyroid hormones exert their effects through the regulation of genes involved in the differentiation of many organs, including brain, muscle, heart, liver, adipose tissue and skin, and controlling carbohydrate / lipid metabolism, protein transcription and basal metabolism [10]. Their plasma concentrations not only depend on direct thyroid output but are also on peripheral tissue concentrations of Selenium $(\mathrm{Se})$ a trace element playing a major role in thyroid hormone metabolism, as well as, in protection from oxidative stress and inflammation after being incorporated into type 1 and type 2 seleno-protein enzymes including glutathione peroxidase $[11,12]$.

Moreover, as suggested by several studies, Se might also exert an inhibiting effect on adipocyte hypertrophy and adipogenesis, and obesity has been reported to be inversely associated with circulating Se and tissue glutathione peroxidase levels [13-15]. A possible underlying mechanism might be Se insulin-mimicking properties through protein kinase activation and by Se-deficiency association with insulin resistance [16-18]

When taking together all of the above, we decided to analyze the effects of Se administration upon obese subjects with SH. The primary endpoint of our study was Se-dependent weight loss; the secondary endpoints were eventually occurring (i) TSH decrease, and (ii) body composition improvement as assessed by bioimpedance analysis.

\section{Materials and Methods}

\section{Patients, diet, and measures}

This was a double-blind, placebo-controlled study conducted in accordance with the Helsinki Declaration. The study was formally approved by the Ethics Committee of the University of Campania "Luigi Vanvitelli", Naples, Italy.

Inclusion criteria were: age between 18 and 70 years; obesity (body mass index (BMI) $>30 \mathrm{~kg} / \mathrm{m}^{2}$ ); type 2 diabetes mellitus under oral hypoglycemic agents and HbAlc between 6.5\% and 7.5\%; insulin resistance index according to the Homeostatic Model Assessment (HOMA-IR) >2.5 [19].

Exclusion criteria were: evidence of thyroid autoimmunity (high Anti-thyroglobulin antibodies [Ab-TG] and Anti-peroxidase antibodies [Ab-TPO] titers); type 1 diabetes; known Se hypersensitivity / intolerance; previous cardiovascular events; pregnancy; lactation; hypoglycemic or cholesterol-lowering or contraceptive treatment; previous bariatric surgery; history of severe hepatic, renal or cardiac diseases; any malignancies.

The estimated sample size expected to yield a statistically significant result for this study calculated on the basis of the primary outcome endpoint to have a power of $90 \%$ with an alpha error of 0.02 was 40 paired subjects. One hundred and twenty-two patients meeting the enrollment criteria and giving their informed consent were selected to take into account the presence of secondary outcomes and expected eventually occurring dropouts. They were randomized to receive either treatment or placebo. 16 did not show up on the starting day, 4 did not complete the full study period, and 2 discontinued treatment spontaneously after a few weeks despite no side effects. As a result 50 pairs of subjects were finally involved in the 52 week study, randomized to take each day after lunch either L-selenio-methionine $83 \mathrm{mcg}$ (Se Group, SG) or placebo (Placebo Group, PG) through size, shape, color, smell, and taste matched tablets (Figure 1).

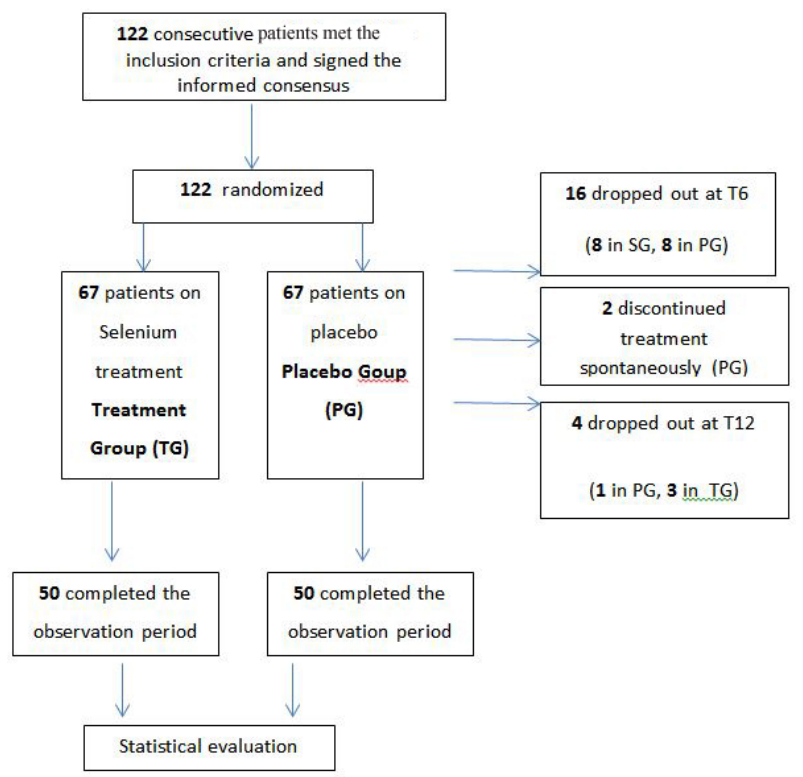

Figure 1: Flow chart depicting patients enrollment procedure 
In greater detail, both medication and placebo packaging intended to couples of paired subjects were prepared by the hospital pharmacy and to each box of pills a serial number was attributed as supplied by a generator of pairs of random numbers corresponding to a specific package of drug and placebo. This way each component of each pair of matched subjects was blindly administered either drug or placebo.

During the study all patients received a low-calorie diet (20-25\% less than the amount of calories required to maintain current weight) characterized by low glycemic index foods and based on a variable percentage of proteins (10-20\%), fat (20-30\% with less than $10 \%$ as saturated fat), and carbohydrates (50-60\% with less than $5 \%$ as sucrose). Individual diet regimens were prepared to try and satisfy participant tastes and wishes as much as possible. Favorite carbohydrate sources were starches with a low glycemic index and high soluble fiber content (35 g/day). All subjects reported to perform at least 30 min a day of predominantly aerobic physical exercise as prescribed.

The following parameters were evaluated at baseline $\left(\mathrm{T}_{0}\right)$ and after $6\left(\mathrm{~T}_{6}\right)$ and 12 months $\left(\mathrm{T}_{12}\right)$ : fasting blood glucose, fasting serum insulin, HOMA-IR, total cholesterol, HDL cholesterol, LDL cholesterol, triglycerides, uric acid, TSH, FT3, FT4, anthropometric measures including weight, height, BMI, and bio-impedance analysis results as reported below.

Serum selenium was estimated by inductively coupled plasma-mass spectrometry as previously described [20]

Bio-impedance analysis (BIA) Abdominal fat was measured using an innovative bio-impedance device (Bia-TANITA AB140 ViScan, BIO) [21] which we also found to be a useful tool in our hands [22]. It consists of a band with four electrodes placed directly on the abdomen, with the subject lying supine. The position of the band was guided by a laser beam from the base unit indicating the navel. Thanks to its high accuracy and repeatability, rather than using any hand-held measuring tape we preferred to have waist circumference (WC) recorded by the base unit itself according to the infrared system [23] along with trunk fat (TF), and percent visceral fat (VF) [24-27].

Safety parameters: AST, ALT, total bilirubin, serum albumin, $\gamma$-glutamyl-transferase, alkaline phosphatase, blood urea nitrogen, serum creatinine, red and white blood cell and platelet count, as well as, all the above mentioned blood parameters were measured using a high performance autoanalyzer (Automatic biochemistry analyzer with integrated system Selectra Pro XL, Elitech, USA) and an automated blood cell counter (Countess II Automated Cell Counter, Thermo Fisher, USA) at baseline and after 6 and 12 months. Side effects were also recorded at baseline and after 6 and 12 months, using a semi-quantitative scale.

Diet adherence: All subjects completed a questionnaire (Q) to evaluate diet adherence during the treatment period. Q consisted of five questions including the frequency of breaches of nutritional advice and the type and amount of food eaten outside the recommended value. Were considered variations from the recommended diet to be acceptable when $\leq$ four per week and within 250 calories each. The questionnaire was previously tested for validity and reliability in a sample of 10 health care workers, verifying the concordance of the answers given by the same subjects to whom Q was administered three times in a two-week period (mean concordance degree of $95+5 \%)$.

Statistics: Results were expressed as means \pm SD or \%. Observed treatment and differences were tested by the repeated measures analysis of variance (rANOVA) integrated by two-tailed paired Student's t-test with 95\% Confidence Intervals (CI) for parametric variables and Mann-Whitney's U test for non-parametric ones. The $\chi^{2}$ test with Yates correction or Fisher Exact test was used to compare categorical variables. A p $<0.05$ was chosen as the least accepted statistical significance level. All the evaluations were performed using IBM SPSS Statistics Version 25 software.

\section{Results}

No significant differences were found between the two treatment groups at baseline, as described in Table I. Good diet and exercise adherence was observed in both groups ( $88 \%$ vs $91 \%$ and $85 \%$ vs $84 \%$ in SG and PG, respectively; p n.s.). Reported side effects were low and quite similar in both groups. In greater detail, transient abdominal distension was reported during the first two weeks by 1 subject in the SG and 2 subjects in the PG, which in fact spontaneously vanished thereafter. No significant changes in safety parameters occurred until $\mathrm{T}_{12}$, nor were observed significant changes in HbA1c in both groups $(<2 \%)$.

\begin{tabular}{|c|c|c|}
\hline & $\begin{array}{c}\text { Control } \\
\text { Group }\end{array}$ & $\begin{array}{c}\text { Selenium } \\
\text { Group }\end{array}$ \\
\hline Subjects (n) & 50 & 50 \\
\hline Male (n) & 12 & 13 \\
\hline Age (year) & $58 \pm 9$ & $57 \pm 8$ \\
\hline BMI (kg/m²) & $34 \pm 2$ & $34 \pm 4$ \\
\hline Smoking habits (n.) & 3 & 5 \\
\hline Systolic BP (mm Hg, M+DS) & $136 \pm 15$ & $137 \pm 13$ \\
\hline Diastolic BP (mm Hg, M+DS) & $82 \pm 9$ & $83 \pm 9$ \\
\hline Fasting Glycemia (mg/dl) & $92 \pm 10$ & $90 \pm 12$ \\
\hline
\end{tabular}




\begin{tabular}{|c|c|c|}
\hline & $\begin{array}{c}\text { Control } \\
\text { Group }\end{array}$ & $\begin{array}{c}\text { Selenium } \\
\text { Group }\end{array}$ \\
\hline HbAlc (\%) & $7+03$ & $7+04$ \\
\hline HOMA-IR & $4.5 \pm 0,8$ & $4.6 \pm 1.0$ \\
\hline Creatinine (mg/dl) & $0.8 \pm 0.2$ & $0.8 \pm 0.3$ \\
\hline AST (IU/l) & $27 \pm 9$ & $25 \pm 9$ \\
\hline ALS (IU/l) & $28 \pm 8$ & $29 \pm 8$ \\
\hline Y-GT (IU/l) & $18 \pm 7$ & $20 \pm 5$ \\
\hline Total cholesterol (mg/dl) & $198 \pm 10$ & $200 \pm 13$ \\
\hline HDL-Cholesterol (mg/dl) & $38 \pm 8$ & $40 \pm 6$ \\
\hline LDL-Cholesterol (mg/dl) & $107 \pm 6$ & $105 \pm 10$ \\
\hline TSH ( $\mu \mathrm{U} / \mathrm{ml})$ & $6.8 \pm 2.4$ & $7.0 \pm 2.1$ \\
\hline FT ${ }_{4}(\mathrm{pmol} / \mathrm{l})$ & $15.1 \pm 2$ & $14.9 \pm 1.9$ \\
\hline FT $(\mathrm{pmol} / \mathrm{l})$ & $4.1 \pm 1.0$ & $4.2 \pm 0.9$ \\
\hline Selenium $(\mu \mathrm{g} / \mathrm{L})$ & $83 \pm 10$ & $82 \pm 13$ \\
\hline Waist circumference $(\mathrm{cm})$ & $120 \pm 7$ & $118 \pm 9$ \\
\hline Trunk fat level $(\%)$ & $48 \pm 6$ & $46 \pm 7$ \\
\hline Visceral fat level $(\%)$ & $24 \pm 7$ & $24 \pm 5$ \\
\hline $24(\mathrm{OH})$ Vitamin-D mmol/l) & $15 \pm 6$ & $14 \pm 6$ \\
\hline
\end{tabular}

Table 1: General parameters of patients enrolled at baseline; data are given as $n$. or Mean \pm SD. Between the two groups no statistically significant differences were found

At $\mathrm{T}_{12}$ Se plasma concentrations were quite similar to baseline in the PG $(84 \pm 12 v s 83 \pm 10 \mu \mathrm{g} / \mathrm{L}$, p n.s.), and significantly higher that baseline in the SG $(101 \pm 10 v s 82 \pm 13$; ( $>0.01)$. The main results observed after 52 weeks are shown in Figures 2 and 3 . In greater detail, a significantly lower BMI (difference from baseline $24.1 \%$ vs $-8.5 \%$, respectively; $\mathrm{p}<0.001$ ) and HOMA-IR (difference from baseline $-54.4 \%$ vs $-11 \%$, respectively; $\mathrm{p}<0.0001$ ) was observed in the SG than in the PG. The decrease in BMI was significantly associated with decreased TSH (Figure 2), implying a difference from baseline of $-42.8 \%$ in the SG vs - $11 \%$ in the PG, respectively $(\mathrm{p}<001)$. Conversely, no FT4 changes were found either in the PG $(15.1 \pm 2.0 \mathrm{pmol} / \mathrm{l}$ at T0 vs $14.6 \pm 2.0 \mathrm{pmol} / \mathrm{l}$ at T12, p n.s.) or in SG $\left(14.9 \pm 1.9 \mathrm{pmol} / \mathrm{l}\right.$ at $\mathrm{T}_{0} v s 14.7 \pm 2.2 \mathrm{pmol} / \mathrm{l}$ at $\mathrm{T}_{12}, \mathrm{p}$ n.s.) and, similarly, no FT3 changes were found either in the PG (4.1 $\pm 1.0 \mathrm{pmol} / \mathrm{l}$ at $\mathrm{T}_{0}$ vs $4.3 \pm 1.0 \mathrm{pmol} / \mathrm{l}$ at $\mathrm{T}_{12}$, $\mathrm{p}$ n.s.) or in SG $\left(4.2 \pm 0.9 \mathrm{pmol} / \mathrm{l}\right.$ at $\mathrm{T}_{0} v s 4.5 \pm 0.9 \mathrm{pmol} / \mathrm{l}$ at $\mathrm{T}_{12}, \mathrm{p}$ n.s. $)$. The Figure 4 depicts the $\%$ effect of Se on WC, TF and VF in both SG and PG. All the above mentioned parameters, despite significantly decreasing in both groups, did so more prominently in the SG. TSH kept stable in the CG but significantly decreased after treatment in the SG only (Figure 5).

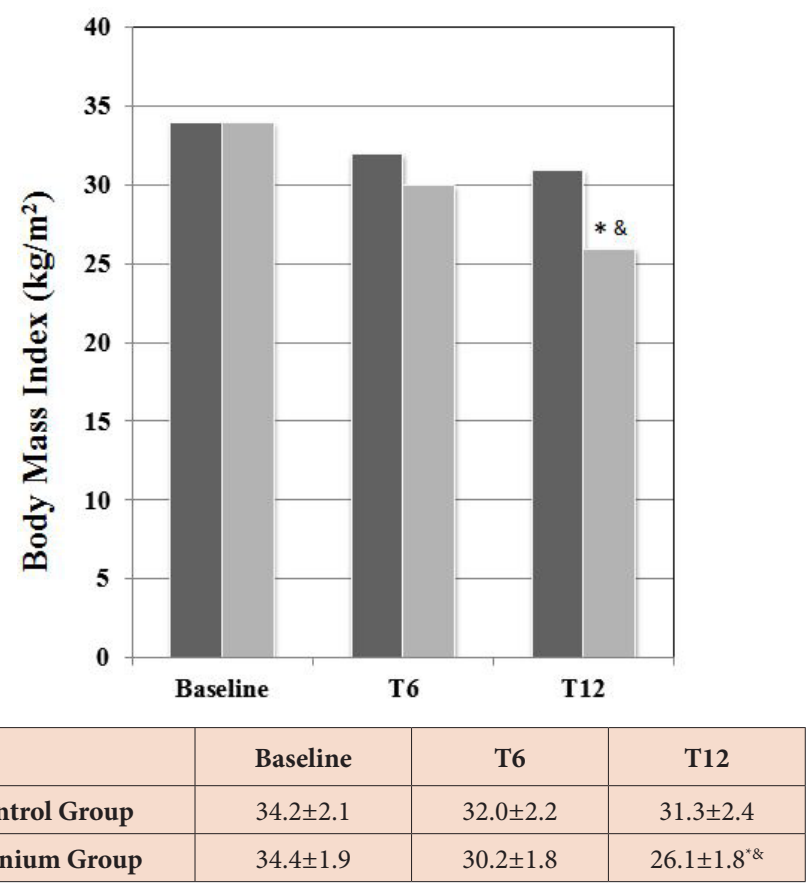

Figure 2: $\mathrm{BMI}\left(\mathrm{kg} / \mathrm{m}^{2} ; \mathrm{M} \pm \mathrm{SD}\right)$ : comparison between Placebo and Selenium Groups during the 12 -months treatment period $\left({ }^{*} \mathrm{p}<0.01\right.$ vs Baseline; ${ }^{*} \mathrm{p}<0.01$ vs Controls; Dark Bars $=$ Control Group, Light Bars = selenium Group) 


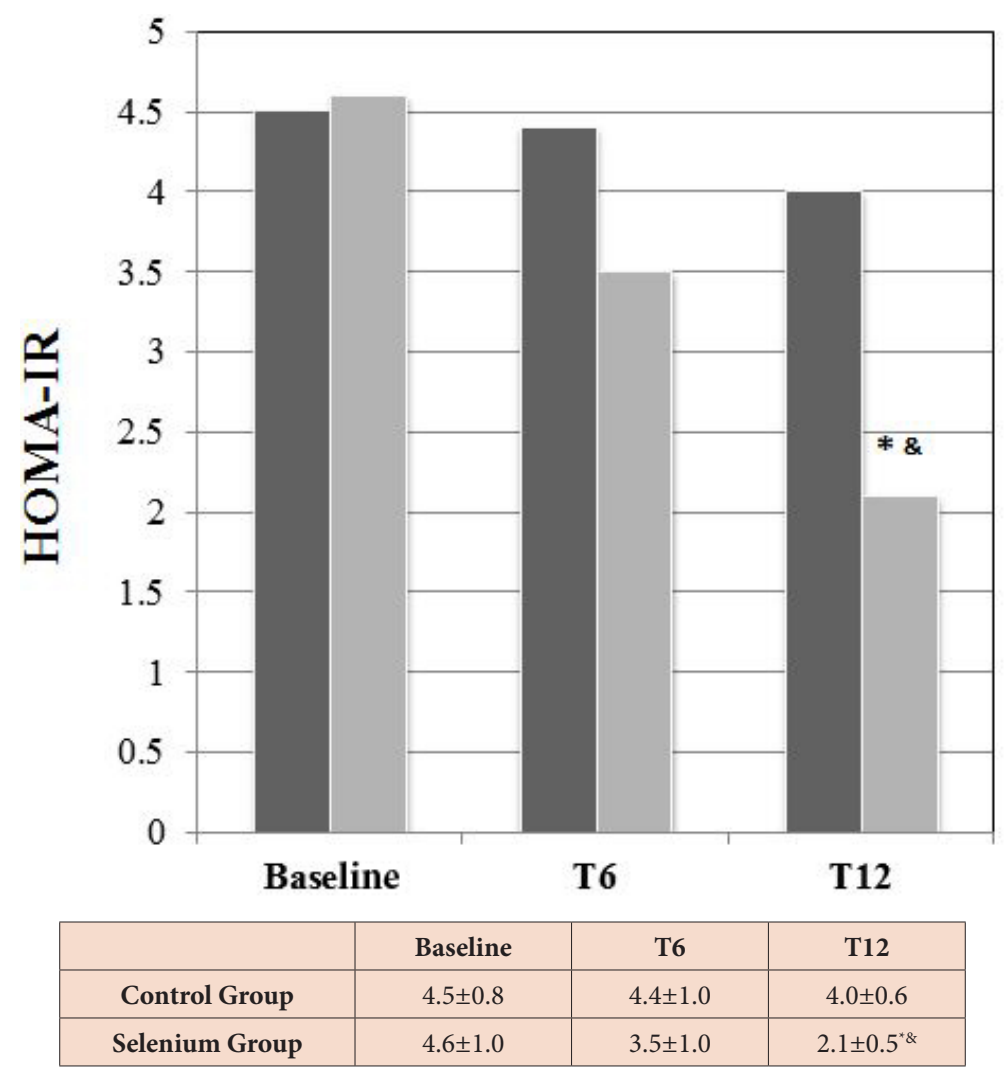

Figure 3: HOMA-IR $(\mathrm{M} \pm \mathrm{SD})$ : comparison between Placebo and Selenium Groups during the 12 -months treatment period $\left({ }^{*} \mathrm{p}<0.01\right.$ vs Baseline; ${ }^{*} \mathrm{p}<0.01$ vs Controls; Dark Bars $=$ Control Group, Light Bars $=$ selenium Group)

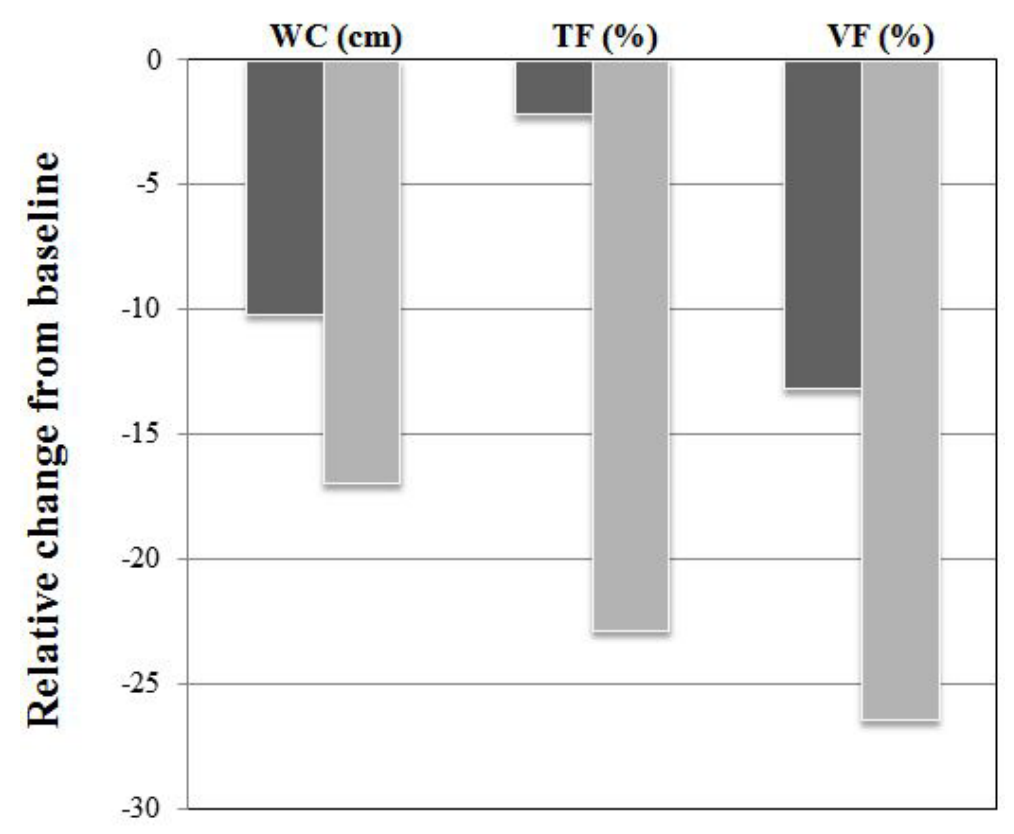

\begin{tabular}{|c|c|c|c|c|c|c|}
\hline & WC $(\mathbf{c m})$ & $\begin{array}{c}\text { within-group } \\
\mathbf{p}\end{array}$ & TF (\%) & $\begin{array}{c}\text { within-group } \\
\mathbf{p}\end{array}$ & VF (\%) & $\begin{array}{c}\text { within-group } \\
\mathbf{p}\end{array}$ \\
\hline Control Group & -10.2 & $<0.05$ & -2.2 & n.s. & -13.2 & $<0.05$ \\
\hline Selenium Group & -17.0 & $<0.001$ & -22.9 & $<0.001$ & -26.5 & $<0.001$ \\
\hline Between- group p & \multicolumn{2}{|c|}{$<0.001$} & \multicolumn{2}{|c|}{$<0.001$} \\
\hline
\end{tabular}

Figure 4: T12 Changes from baseline (\%) as for waist circumference (WC, cm), trunk fat (TF, \%) and visceral fat (VF, \%) in Selenium Group (Dark Bars) vs Placebo Group (Light Bars) 


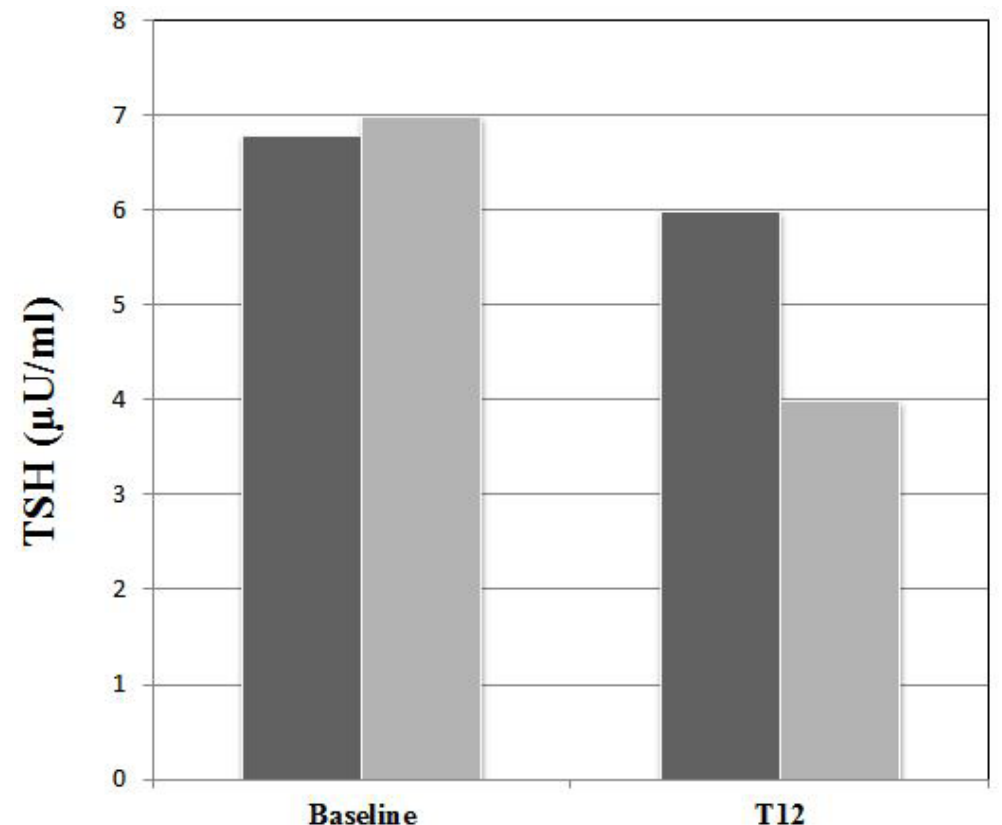

\begin{tabular}{|c|c|c|}
\hline & Baseline & T12 \\
\hline Control Group & $6.8 \pm 2.4$ & $6.0 \pm 1.3$ \\
\hline Selenium Group & $7.0 \pm 2.1$ & $4.0 \pm 1.1$ \\
\hline p & n.s. & $<0.01$ \\
\hline
\end{tabular}

Figure 5: TSH $(\mu \mathrm{U} / \mathrm{ml} ; \mathrm{M} \pm \mathrm{SD})$ : group comparison during the 12-month treatment period (Dark Bars $=$ Placebo Group, Light Bars = Selenium Group)

A significant correlation was found between TSH and BMI decrease rate in all patients participating in the study ( $\mathrm{r}=0,847, \mathrm{p}<0.01)$, being those from the SG contributing to the greatest decrease of both BMI and TSH at $\mathrm{T}_{12}$ (Figure 6). A similar significant correlation was observed between HOMA-IR and TSH decrease rates $(r=0.921, p<0.01)$ (Figure 7).

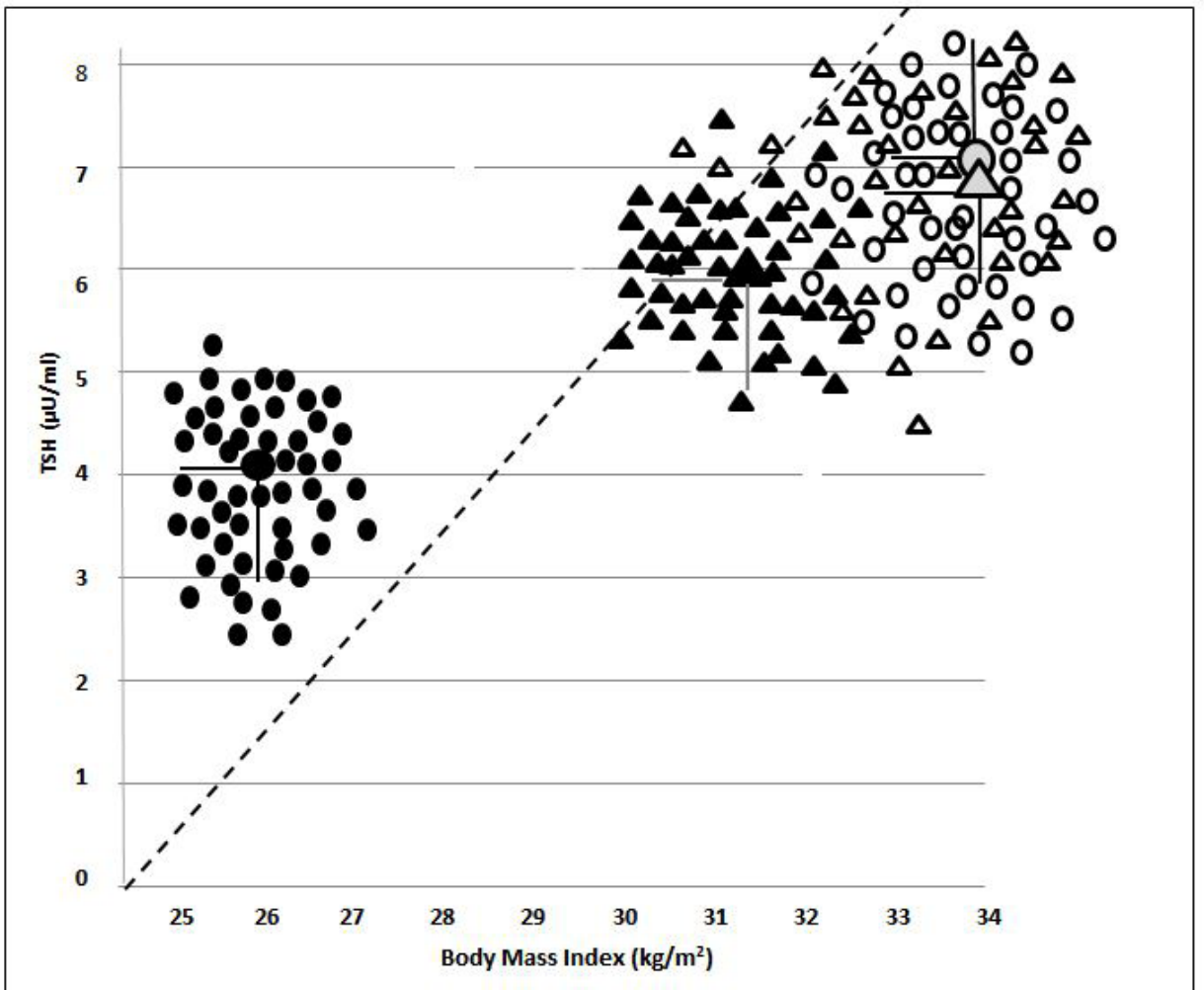

Controls Group at baseline=open circle; at end of follow-up black circle, $p<0.001$; Selenium Group at baseline $=0$ open triangle; open circle; at end of follow-up black triangle, $p<0.05$. Horizontal and vertical bars $=$ half of $S D$

Figure 6: Correlation between mean values (+SD) of thyroid-stimulating hormone (TSH) and body mass index (BMI) in 100 patients with subclinical hypothyroidism (SH) and obesity 


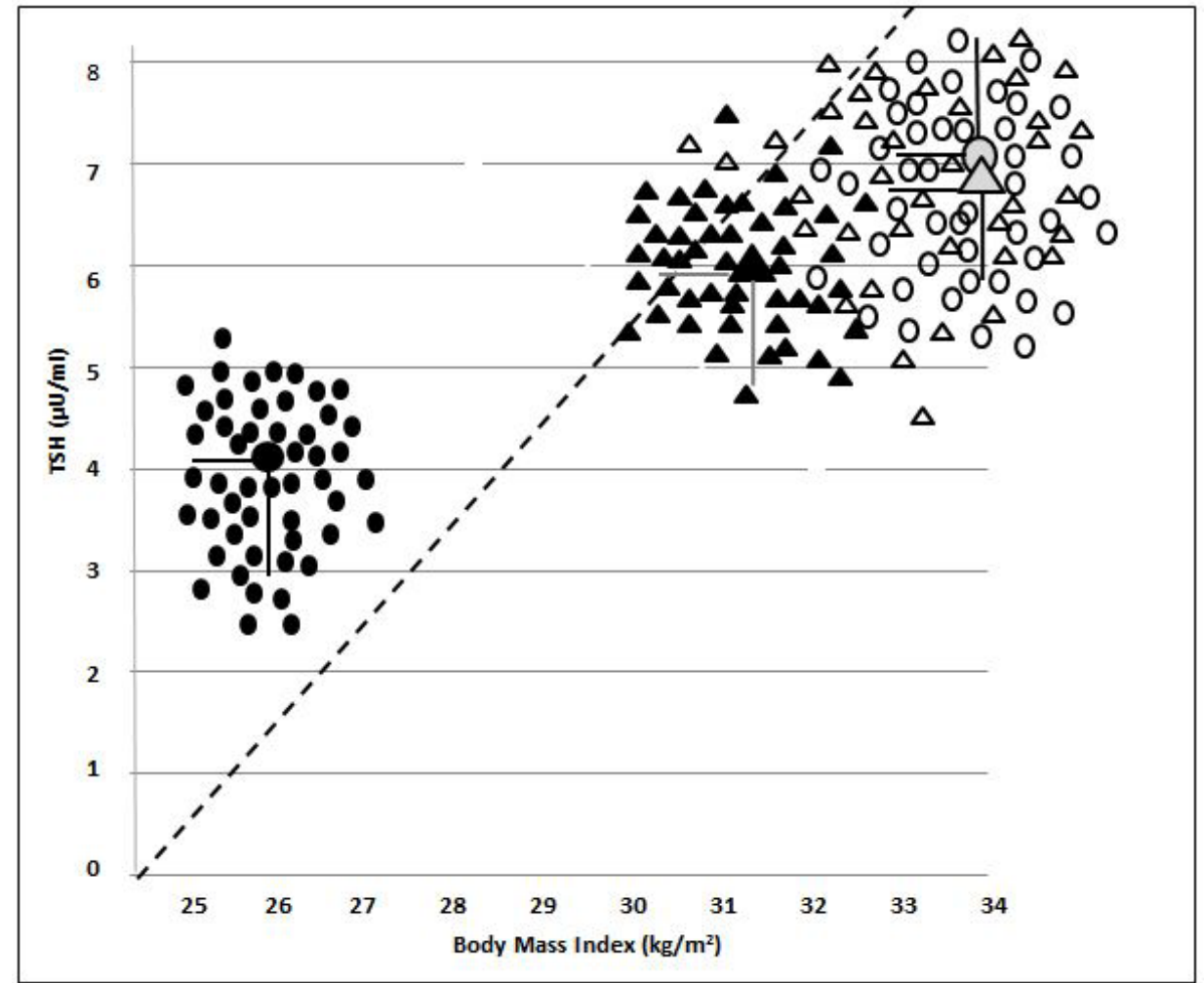

Placebo Group: at baseline = open circle; at end of follow-up = black circle, $p<0.001$; Selenium Group: at baseline = open triangle; at end of follow-up = black triangle, $p<0.05$. Horizontal and vertical bars $=$ single SDs.

Figure 7: Correlation between mean values $( \pm \mathrm{SD})$ of thyroid-stimulating hormone $(\mathrm{TSH})$ and HOMA-IR index in 100 patients with subclinical hypothyroidism (SH) and obesity

\section{Conclusion}

In our study, selenium supplementation inversely associated with anthropometric (BMI, WC) and metabolic (HOMA-IR) indexes. These results provide indirect support to the fact that insulin resistance and visceral adiposity may induce selenium deficiency [28-29] as well as, that insulin resistance might indeed depend on it [18,30,31]. In fact, observational studies meant at assessing any eventually occurring association of Se concentrations with central obesity or insulin resistance provided inconsistent results. Conversely, two relatively short duration (6-8 weeks) intervention studies reported on significantly reduced fasting blood insulin levels and HOMA-IR after Se supplementation [32].

What is really new in our study is the observed visceral fat decrease after Se supplementation, strongly supporting our original hypothesis that visceral adiposity might depend on Se deficiency.

Selenium is present in seleno-proteins, which play a vital role for antioxidant and anti-inflammatory activities and contribute to anti-diabetic activity [33]. Selenium supplementation improves blood glucose and blood insulin levels, and inhibits gluconeogenesis in diabetic rats $[33,34]$. The Se concentration expected to maximize seleno-enzyme antioxidant activity has been determined to be $95 \mathrm{mg} / \mathrm{L}$ on average (range 89-114 mg/L) [36-38], i.e. very similar to the level attained in our study experiment. Therefore, we can conclude that at physiological concentrations selenium is involved in the metabolic activities responsible for maintaining blood glucose compensation opposite to what observed at higher concentrations, associating with an increase in diabetes prevalence according the results of a post-hoc analysis of the National Health and Nutrition Examination Survey (NHANES) [38]. In addition, 1999 to 2004 NHANES data demonstrated that people on a selenium-deficient diet were at higher risk of overweight [39]; lastly, a positive correlation was described between Se concentrations and BMI, as well as an inverse association between anthropometric indexes and serum/plasma selenium [39-42]. In our study, the efficacy of Se supplementation can be detected in its primary action on the conversion metabolism (de-iodination) of the pro-hormone thyroxine to the active form tri-iodo-thyronine, supporting the theory that an adequate plasma selenium concentration is useful to prevent excessive weight. This theory is reinforced by the consideration that, in obese patients, (reduced) plasma selenium concentrations could be due to habitual and excessive consumption of high-fat and high-sugar foods, as well as high-sugar drinks [43,44].

Although the effects of Se on body fat metabolism have not been fully elucidated yet, there is evidence relating Se to adipogenesis, i.e. the trace element is thought to be able to inhibit adipogenesis by reducing the expression of m-RNA encoding for PPAR and fatty acid synthase, while stimulating the activation of tissue growth factor (TGF) $[45,46]$. 


\section{Limitations}

On the basis of speculative observations, it is essential to highlight the presence of limitations of our work. First, given the design of the study, we did not establish a causal relationship between selenium concentration and visceral fat; second, although the results were adjusted for the most likely confounding factors, we might have ignored further potentially involved additional factors; third, we reduced the study costs by assessing insulin resistance through HOMA-IR, a widely used, low accuracy parameter, rather than the gold standard method represented by the dynamic euglycemic-hyperinsulinemic clamp.

Our study confirmed previously reported association between Se treatment and TSH level normalization in the absence of any changes in circulating FT4 concentrations The latter results agree with those coming from other studies on Se-related enhanced T4 to T3 de-iodination [11] and on thyroid hormone effects in obese patients with moderate hypothyroidism [44].

The most relevant outcome of our study, however, was the first evidence that selenium supplementation per se decreases \% abdominal fat depots as reflected both by waist circumference, its widely used surrogate marker, and by bio-impedance derived \%VF measurements.

\section{Compliance with ethical standards}

Ours was a spontaneous, unconditioned study organized and supported by a special research grant of University of Campania "Luigi Vanvitelli", Naples, Italy.

\section{Ethical standard}

This study was conducted in conformance with good clinical practice standards. The study was led in accordance with the Declaration of Helsinki 1975, as revised in 2008, and was approved all the Ethics Committees of the Centers participating in the study.

\section{Human and animal rights}

All followed procedures were in accordance with the ethical standards of the responsible committee on human experimentation (institutional and national).

\section{Informed consent}

Written informed consent was obtained from all participants before enrollment.

\section{Acknowledgment}

The study was supported by the AMD (Association of Medical Diabetology) Foundation Rome. No additional funding was received for this further analysis.

The component of Italian Study Group on Injection Techniques are acknowledged too for critical reading of the manuscript: Stefano De Riu, Nicoletta De Rosa, Giorgio Grassi, Gabriella Garrapa, Laura Tonutti, Katja Speese, Lia Cucco, Maria Teresa Branca, Amodio Botta.

\section{References}

1. Allied Health Sciences Section Ad Hoc Nutrition C, Aills L, Blankenship J, Buffington C, Furtado M, et al. (2008) ASMBS Allied Health Nutritional guidelines for the surgical weight loss patient. Surg Obes Relat Dis 4: S73-108.

2. Janković D, Wolf P, Anderwald CH, Winhofer Y, Promintzer-Schifferl M, et al. (2012) Prevalence of endocrine disorders in morbidly obese patient and the effects of bariatric surgery on endocrine and metabolic parameters. Obes Surg 22: 62-9.

3. Tseng FY, Lin WY, Lin CC, Lee LT, Li TC, et al. (2012) Subclinical hypothyroidism is Associated with increased risk for all-cause and cardiovascular mortality in adults. J Am Coll Cardiol 60: 730-7.

4. Biondi B, Palmieri EA, Lombardi G, Fazio S (2002) Effects of subclinical thyroid dysfunction on the heart. Ann Intern Med 137: 904-14.

5. Biondi B, Cooper DS (2008) The clinical significance of subclinical thyroid dysfunction. Endocr Rev 29: 76-131.

6. Janssen IM, Homan J, Schijns W, Betzel B, Aarts EO, et al. (2015) Subclinical hypothyroidism and its relation to obesity in patients before and after Roux-en-Y gastric bypass. Surg Obes Relat Dis 11: 1257-63.

7. Kok P, Roelfsema F, Frolich M, Meinders AE, Pijl H (2005) Spontaneous diurnal thyrotropin secretion is enhanced in proportion to circulating leptin in obese premenopausal women. J Clin Endocrinol Metab 90: 6185-91.

8. Kok P, Roelfsema F, Frölich M, van Pelt J, Meinders AE, et al. (2009) Bromocriptine reduces augmented thyrotropin secretion in obese premenopausal women. J Clin Endocrinol Metab 94: 1176-81.

9. Rotondi M, Leporati P, La Manna A, Pirali B, Mondello T, et al. (2009) Raised serum TSH levels in patients with morbid obesity: is it enough to diagnose subclinical hypothyroidism? Eur J Endocrinol 160: 403-8.

10. Mullur R, Liu Y, Brent GA (2014) Thyroid hormone regulation of metabolism. Physiol Rev 94: 355-82.

11. Schomburg L, Kohrle J (2008) on the importance of selenium and iodine metabolism for thyroid hormone biosynthesis and human health. Mol Nutr Food Res 52: 1235-46. 
12. Touat-Hamici Z, Legrain Y, Bulteau AL, Chavatt L (2014) Selective up-regulation of human selenoproteins in response to oxidative stress. J Biol Chem 289: 14750-61.

13. Kim JE, Choi SI, Lee HR, Hwang IS, Lee YJ, et al. (2012) Selenium significantly inhibits adipocyte hypertrophy and abdominal fat accumulation in OLETF rats via induction of fatty acid. Biol Trace Elem Res 150: 360-70.

14. Kim CY, Kim GN, Wiacek JL, Chen CY, Kim KH (2012) Selenate inhibits adipogenesis through induction of transforming growth factor-_1 (TGF-_1) signaling. Biochem Biophys Res Commun 426: 551-57.

15. Spina A, Guallar E, Rayman MP, Tigbe W, Kandala NB, et al. (2013) Anthropometric indices and selenium status in British adults: The UK National Diet and Nutrition Survey. Free Radic Biol Med 65: 1315-21.

16. Beckett GJ, Arthur JR (2005) Selenium and endocrine systems J Endocrinol 184: 455-65.

17. Ahn B-I, Kim MJ, Koo HS, Seo N, Joo N-S, et al. (2014) Serum zinc concentration is inversely associated with insulin resistance but not related with metabolic syndrome in nondiabetic Korean adults. Biol Trace Elem Res 2014; 160: 169-75.

18. Gao H, Hagg S, Sjogren P, Lambert PC, Ingelsson E, et al. (2014) Serum selenium in relation to measures of glucose metabolism and incidence of type 2 diabetes in an older Swedish population. Diabetic Med 31: 787-93.

19. Matthews DR, Hosker JP, Rudenski AS, Naylor BA, Treacher DF, et al. (1985) Homeostasis model assessment: insulin resistance and $\beta$-cell function from fasting plasma glucose and insulin concentrations in man. Diabetologia 28: 412-19.

20. Yadav C, Manjrekar PA, Agarwal A, Ahmad A, Hegde A, et al. (2017) Association of Serum Selenium, Zinc and Magnesium Levels with Glycaemic Indices and Insulin Resistance in Pre-diabetes: a Cross-Sectional Study from South India. Biol Trace Elem Res 175: 65-71.

21. Vitturi N, Soattin M, De Stefano F, Vianello D, Zambon A, et al. (2015) Ultrasound, anthropometry and bioimpedance: a comparison in predicting fat deposition in non-alcoholic fatty liver disease. Eat Weight Disord 20: 241-7.

22. Guarino G, Strollo F, Carbone L, Della Corte T, Letizia M, et al. (2017) Bioimpedance analysis, metabolic effects and safety of the association Berberis aristata/ Bilybum marianum: a 52-week double-blind, placebo-controlled study in obese patients with type 2 diabetes. J Biol Regul Homeost Agents 31: 495-502.

23. Schutz Y, Sarafian D, Miles JL, Montani JP, Dulloo AG (2012) Non-contact assessment of waist circumference: will tape measurements become progressively obsolete? Eur J Clin Nutr 66: 269-72.

24. Camina Martín MA, de Mateo Silleras B, Nescolarde Selva L, Barrera Ortega S, Domínguez Rodríguez L, et al. (2015) Bioimpedance vector analysis and conventional bioimpedance to assess body composition in older adults with dementia. Nutrition 31: 155-9.

25. Savegnago Mialich M, Faccioli Sicchieri JM, Jordao AA (2014) Analysis of Body Composition: A Critical Review of the Use of Bioelectrical Impedance Analysis. Int J Clini Nutri 2: 1-10.

26. Verney J, Metz L, Chaplais E, Cardenoux C, Pereira B, et al. (2016) Bioelectrical impedance is an accurate method to assess body composition in obese but not severely obese adolescents. Nutr Res 36: 663-70.

27. Gómez-Ambrosi J, González-Crespo I, Catalán V, Rodríguez A, Moncada R, et al. (2018) Clinical usefulness of abdominal bioimpedance (ViScan) in the determination of visceral fat and its application in the diagnosis and management of obesity and its comorbidities. Clin Nutr 37: 580-9.

28. Wiernsperger N, Rapin JR (2010) Trace elements in glucometabolic disorders: an update. Diabetol Metab Syndr 2: 70.

29. Ortega RM, Rodríguez-Rodríguez E, Aparicio A, Jiménez-Ortega AI, Palmeros C, et al. (2012) Young children with excess of weight show an impaired selenium status. Int J Vitam Nutr Res 82: 121-9.

30. Ventura M, Melo M, Carrilho F (2017) Selenium and Thyroid Disease: From Pathophysiology to Treatment. Int J Endocrinol 2017: 1297658.

31. Ahn BI, Kim MJ, Koo HS, Seo N, Joo NS, et al. (2014) Serum zinc concentration is inversely associated with insulin resistance but not related with metabolic syndrome in nondiabetic Korean adults. Biol Trace Elem Res 160: 169-75.

32. Alizadeh M, Safaeiyan A, Ostadrahimi A, Estakhri R, Daneghian S, et al. (2012) Effect of L-arginine and selenium added to a hypocaloric diet enriched with legumes on cardiovascular disease risk factors in women with central obesity: a randomized, double-blind, placebo-controlled trial. Ann Nutr Metab 60: 157-68.

33. Pirola I, Gandossi E, Agosti B, Delbarba A, Cappelli C (2016) Selenium supplementation could restore euthyroidism in subclinical hypothyroid patients with autoimmune thyroiditis. Endokrynol Pol 67: 567-71.

34. Bitiktas S, Tan B, Batakcı M, Kavraal S, Dursun N, et al. (2016) Effects of selenium treatment on 6-n-propyl-2-thiouracil-induced impairment of long-term potentiation. Neurosci Res 109: 70-6.

35. Zeng J, Zhou J, Huang K (2009) Effect of selenium on pancreatic proinflammatory cytokines in streptozotocin-induced diabetic mice. J Nutr Biochem 20: 5306.

36. Wang XL, Yang TB, Wei J, Lei G-H, Zeng C, et al. (2016) Association between serum selenium level and type 2 diabetes mellitus: a non-linear dose-response meta-analysis of observational studies. Nutr J 15: 48.

37. Assis BS, Jairza JMB, Lopes JA, Roriz AKC, Melo AL, et al. (2018) Micronutrient intake in elderly living in nursing homes. Nutr Hosp 35: 59-64.

38. Laclaustra M, Navas-Acien A, Stranges S, Ordovas JM, Guallar E (2009) Serum selenium concentrations and diabetes in U.S. adults: National Health and Nutrition Examination Survey (NHANES) 2003-2004. Environ Health Perspect 117: 1409-13.

39. Bucholz EM, Desai MM, Rosenthal MS (2011) Dietary intake in Head Start vs. non-Head Start preschool-aged children: Results from the 1999-2004 National Health and Nutrition Examination Survey. J Am Diet Assoc 111: 1021-30.

40. Ortega RM, Rodríguez-Rodríguez E, Aparicio A, Jiménez-Ortega AI, Palmeros C, et al. (2012) Young children with excess of weight show an impaired selenium status. Int J Vitam Nutr Res 82: 121-9.

41. Stranges S, Sieri S, Vinceti M, Grioni S, Guallar E, et al. (2010) A prospective study of dietary selenium intake and risk of type 2 diabetes. BMC Public Health 10: 564 .

42. Azab SF, Saleh SH, Elsaeed WF, Elshafie MA, Sherief LM, et al. (2014) Serum trace elements in obese Egyptian children: A case-control study. Ital J Pediatr 40: 20.

43. Rangan AM, Schindeler S, Hector DJ, Gill TP, Webb KL (2009) Consumption of "extra" foods by Australian adults: Types, quantities and contribution to energy and nutrient intakes. Eur J Clin Nutr 63: 865-71.

44. Muegge CR, Brennan KM, Schoonmaker JP (2017) Supplementation of organic and inorganic selenium to late gestation and early lactation beef cows effect on progeny feedlot performance and carcass characteristics. J Anim Sci 95: 1356-62. 


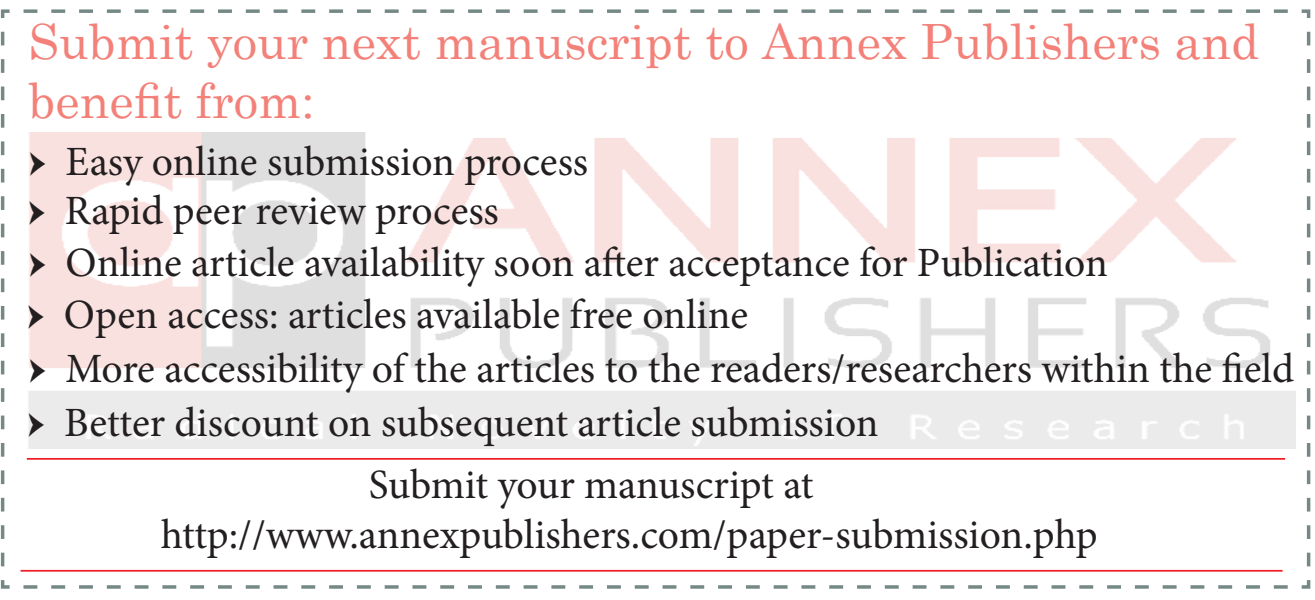

